This is a self-archived version of an original article. This version may differ from the original in pagination and typographic details.

Author(s): Aaltola, Pasi; Manninen, Ari

Title: Drawing the premises for personalized learning : illustrations of management and accounting

Year: 2021

Version: Published version

Copyright: (c) 2020 the Authors

Rights: $C C$ BY 4.0

Rights url: https://creativecommons.org/licenses/by/4.0/

Please cite the original version:

Aaltola, P., \& Manninen, A. (2021). Drawing the premises for personalized learning : illustrations of management and accounting. Journal of Accounting Education, 54, Article 100698.

https://doi.org/10.1016/j.jaccedu.2020.100698 


\title{
Drawing the premises for personalized learning: Illustrations of management and accounting
}

\author{
Pasi Aaltola*, Ari Manninen \\ University of Jyväskylä, School of Business and Economics, Finland
}

\section{A R T I C L E I N F O}

\section{Article history:}

Received 25 September 2019

Received in revised form 1 November 2020

Accepted 3 November 2020

\section{Keywords:}

Accounting

Education

Drawing

Accounting education

Managerial work

Management accounting

Visual methods

\begin{abstract}
A B S T R A C T
This paper reports on a teaching innovation using participant-generated drawings. Experienced managers were asked to produce a drawing to illustrate their work from an accounting perspective. The drawings were then used to make the managerial context of the participants the explicit starting point for personalized executive learning. This study is the first in the sphere of accounting education and research to take drawing seriously as a learning method. The results of the experiment show how drawing can be further used as a tool in management education by facilitating the visualization of the managerial contexts participants work within.
\end{abstract}

(C) 2020 The Authors. Published by Elsevier Ltd. This is an open access article under the CC BY license (http://creativecommons.org/licenses/by/4.0/).

\section{Introduction}

This paper reports on a teaching innovation in the field of accounting and managerial work. Participants in an executive MBA accounting course completed a learning assignment using visualization, which involved experienced managers producing a drawing to illustrate their managerial work from an accounting perspective. This article aims to contribute to the literature by exploring the potential of drawing as a novel pedagogical approach in management education, a field accused of being overly focused on traditional teaching models and approaches (e.g., Asik-Dizdar, 2015; Bennis \& O'Toole, 2005; Khurana, 2007; Mintzberg, 2004; Pfeffer \& Fong, 2002; David, David, David, 2011; Rubin \& Dierdorff, 2009; Miley \& Read, 2018; Minocha, Reynolds, \& Hristov, 2017). More specifically, despite recent innovations (e.g., Krom \& Williams, 2011; Tucker, 2017), the accounting elements of MBA programs have also been criticized for a lack of innovativeness (e.g., Böer, 2000; Hermanson, Hermanson, Alsup, 1998). The critical importance of accounting education research and utilizing its findings to develop teaching has been highlighted as one area in need of improvement (Ravenscroft, Rebele, St. Pierre, 2008; Rebele and St Pierre, 2015).

Several suggestions have been made to develop management education for experienced learners so that it better recognizes the experience of the participants as a strength (Mintzberg, 2004; Carvin, 2007; Minocha et al., 2017; Roglio \& Light, 2009; Ruane, 2016; Currie \& Knights, 2003; Tushman, O’Reilly, Fenollosa, Kleinbaum \& McGrath, 2007). However, there remains an empirical deficit in pedagogical innovations in personalized learning. This paper reports an experiment adopting a personalized learning approach with the use of participant-generated drawings that aim to highlight participants' experi-

\footnotetext{
* Corresponding author at: P.O. Box 35, FI-40014 University of Jyväskylä, Finland.

E-mail address: pasi.aaltola@jyu.fi (P. Aaltola).
} 
ences, beliefs, and understandings (alongside becoming more aware of them) and relate them to the learning process on a personal level.

Humans are visual creatures; our capacity to process information visually exceeds the capability of other senses. In working life, visual modes of representation are becoming more widespread, driven also by the development in digital working environments and presentation technologies. However, the process of developing pictorial presentations has traditionally been viewed merely as a necessary skill set in work related to design (Purcell \& Gero, 1998). Despite the pervasiveness of visual information in contemporary society, the importance of producing visualizations and utilizing such approaches in managerial work has received scant attention in the research literature. Few studies have been done on using drawings and other forms of visuals in an organizational and professional life context (for notable exceptions, see Bryans \& Mavin, 2006; Bowen, 2016; Han \& Liang, 2015; Clarke \& Holt, 2017) and little attention has been paid to the role of drawing in the process of learning. To date, the visual mode of meaning construction has remained largely unexplored in management studies (Meyer, Höllerer, Jancsary, \& Leeuwen, 2013).

This research responds to many calls for further study on the use of visuals in accounting and management research (Quattrone, 2009; Busco \& Quattrone, 2014; Garreau, Mouricou, \& Grimand, 2015; Meyer \& Höllerer, Jancsary, \& Leeuwen, 2013; Davison \& Warren, 2009). Even though drawing has been suggested as a method for qualitative research (Zweifel \& Van Wezemael, 2012; Copeland \& Agosto, 2012; Stiles, 2004), it remains a rarely used approach in facilitating respondents to express their understandings of an issue or phenomenon. This study introduces drawing to a new sphere: an executive learners' accounting course.

This paper presents unique data. The drawings produced by the participants show how they understood their managerial work in an accounting context. The illustrations are examined in content as well in the form of visualization with an interpretative analysis approach (Hatch, 2002). Using a collective construal approach, the findings were also discussed with the participants in order to make more sense of the drawings. The primary focus of this study, however, is to examine the drawing experiment as a pedagogical innovation. Therefore, the paper reports critically on the execution and outcomes of the learning experiment conducted with the participants working in managerial roles in various organizations. Our results offer an illuminating example of developing accounting education by highlighting the individual managerial contexts of executive students which form the bases for learning.

The findings of this paper suggest that drawing can be used as an approach in personalized learning that is grounded in the learner's managerial work context. The managerial work context sets starting points and even demarcates learning, but also establishes the essential directions that are meaningful to a manager thinking about accounting and what constitutes building financial success. Conceptualizing one's understandings by drawing offers a novel approach, different from traditional written or spoken word approaches, which have dominated management research and education. Visual expression triggers a sensemaking process that can be used to respond to our ideas and understandings. Using visualizations can be a learning tool in management education that clarifies those essential elements for both educators and participants. The collective construal approach, where the outcomes of the drawing exercise were afterwards discussed in a group with the participants, also proved to be valuable and provided several avenues for further development of the drawing method.

This paper contributes to the literature by showing how drawing can be used to advance a personalized learning approach, taking the experiences and unique setting of each adult learner into consideration as suggested by various authors (e.g. Minocha et al., 2017; Roglio \& Light 2009; Ruane, 2016; Tushman, O’Reilly, Fenollosa, Kleinbaum, McGrath, 2007). Moreover, visualizations making the managerial context of the participants more explicit also offered a motivational starting point for learning. The drawing experiment helped managerial students to become more aware of their previous understandings and offered the students more opportunity for agency around their learning, therefore fostering experiential learning on a personal level (Kolb, 1984). This article also outlines the limitations of the experiment, and includes several suggestions for further development of the drawing method in executive education. Future research could explore the possibilities of visualizing beyond the traditional written word, an approach that has dominated management research and education. Previous research has paid little attention to the use of drawing in the process of learning. This study is the first in the sphere of accounting education and research to take the approach seriously as a learning method.

\section{Literature review}

\subsection{Criticism of post-graduate management education}

The field of business education has increasingly attracted criticism (e.g., Asik-Dizdar 2015; Bennis \& O'Toole 2005; Khurana, 2007; Mintzberg, 2004; Pfeffer \& Fong, 2002). Henry Mitzberg's book, Managers, Not MBAs (2004) was one of the most influential in stirring up debate. He claimed that traditional classroom teaching is limited in its ability to teach real management, which is primarily a craft to be honed through experience. Others have also found a mismatch between the competencies provided by business education and those required in managerial work (David, David, David, 2011; Rubin \& Dierdorff, 2009), which suggests management education responds poorly to the needs of practicing managers. More recently, Minocha et al. (2017) argue that the criticism of business education remains justified. They suggest that much business school pedagogy is based on academic theoretical content rather than on the context of management practice. The same study proposes the concept of practice intelligence, a blend of professional practice, knowledge, and the business organiza- 
tion context. This suggests that managerial problems and contexts should be taken as a starting point for learning, instead of academic contents and theory. This learner-centric approach is typically applied in executive education where participants are experienced managers studying part-time alongside their managerial responsibilities.

For MBA students, education is more than just a basic qualification and merely a direct instrument for financial gain. For example, it can play a transformational role in students' life stories (Ruth, 2017). Executive MBA programs attract participants with significant managerial experience studying part-time while working in their organizations, which often support their studies. Executive learners typically want more than illustrative and overly general examples. They want their learning to be connected to their work, helping them to improve in their own position and to develop their organizations. Carvin (2007) has outlined several characteristics that make executive teaching different from a conventional MBA education. He describes executive teaching as making more explicit efforts to draw out students' experiences, involving sharing problems they have encountered, and aligning learning with participants' managerial work.

When looking at management learning holistically, formal management education can be seen only as the tip of the learning iceberg, since most learning happens in the working context (Fox, 1997). A situated conceptualization of learning encourages a focus on the practice of management, such things as organizational characteristics, interactive collaboration with peers and power relations (Contu \& Willmott, 2003). This in situ learning in the worlds of practice is essential in the context of executive education. This research positions itself in relation to a personalized learning approach, where the unique setting of each executive learner is taken into consideration in optimizing the learning process. The experiential learning model proposed by Kolb (1984) defines learning as a cyclical process where knowledge is created through the transformation of experience. This idea of learning relies on educators incorporating the experience and contexts of the participants into the learning process (Roglio \& Light 2009; Ruane, 2016), and various methods have been put forward to do so. Currie and Knights (2003) emphasize establishing connections between the content taught and the managerial experience of MBA students through critical pedagogy. They suggest challenging the participants' assumptions regarding how their managerial context can form a basis for learning. Tushman, O’Reilly, Fenollosa, Kleinbaum \& McGrath (2007) emphasize an action learning approach in executive education that leverages the experience of the participants, and they suggest that doing so could restore the legitimacy of business education.

\subsection{Challenges of accounting education with experienced learners}

In addition to postgraduate management education in general, a considerable amount of work has been done specifically on learning and teaching accounting. The accounting content of the MBA programs has been studied from the perspective of the amount of accounting offering and course requirements (Engstrom \& Windal 1985) and exemption policies (Chewning \& Spiller 1999). Böer (2000) reviewed management accounting education and stated that the accounting to be taught needs to change. He suggests that accounting books mainly present things that management accountants find interesting, instead of issues managers consider important in their work. Hermanson, Hermanson, \& Alsup (1998) examined the accounting component in executive MBA (EMBA) programs in the USA. They found accounting was an important part of EMBA curricula but that the coverage of accounting material seemed fairly traditional. Cohen and Holder-Webb (2006) criticize accounting academics for favoring methodologies from the natural sciences, leading to a reduction in the practical relevance of accounting research and education.

In addition to the content focus, the pedagogical choices of accounting education have also been criticized. Accounting educators have raised concerns and reported the problems of teaching accounting in EMBA programs. Pastra (2009) wrote of his experience that teachers and EMBA students sometimes have different socially constructed understandings of what teaching and accounting are. The lack of explanations of why something is as it is in course design creates tensions with the preconceptions of adult executive learners. Pastra (2009) suggests that course facilitators should explain why course content, learning methods and assessment practices have been chosen so as to clarify for students how the choices were made to improve learning. Craig (2001) takes an even stronger stance by reporting an accounting teaching case from an EMBA course where students protested against the learning methods and a workload that they found overly demanding.

Rebele and St. Pierre (2015) state that accounting education research exhibits signs of stagnation, that it is merely describing the status quo and lacks any new contribution and impact on the practice of accounting education. It has been suggested that accounting education researchers should engage more with practitioners (Jones, 2017) and some research does offer responses to the observed challenges. Collett (2000) reports a teaching innovation where a project-based group work was trialed with full-time MBA students to increase the real-world relevance of the learning experience. Tucker (2017) reports the use of analogies to clarify accounting principles to MBA students and to help them engage with the conceptual underpinnings of accounting. Krom and Williams (2011) describe creative writing storytelling as a non-traditional tool in learning accounting. Cooper, Downer, and Faseruk (2013) introduced an integrative accounting course to improve the relevance and pedagogy of teaching accounting in MBA programs. They suggest accounting should be more integrated with and applied in real-life organizational and business settings. These previous approaches shift the learning emphasis from producing accounting information to how and in which contexts it should be used. However, they still focus on the accounting content of the teaching instead of adopting the student's managerial context as a starting point for learning accounting.

Overall, much of the existing research concentrates on conveying the challenges in postgraduate accounting education (Böer, 2000; Hermanson, Hermanson, \& Alsup, 1998; Pastra, 2009; Craig, 2001) or suggesting various ways in which the 
teaching of the contents could be developed (Collett, 2000; Cooper et al., 2013; Carvin, 2007). There is little research on how the executive learners' working life and managerial area of responsibility could offer a starting point for learning. Some work exists on areas like the pedagogical value of reflection in postgraduate accounting education (Brown \& Mccartney, 1998), suggesting that students can gain knowledge about themselves and their actions. How accounting is perceived by nonaccounting managers, however, has been argued to be a rather unexplored area in research (Jönsson, 1998; Hall, 2010). What seems to be missing are pedagogical innovations tapping into executive learners' managerial work as a starting point for learning.

Studies on visual aspects and accounting are also rare yet they are increasing. Schadewald and Limberg (1992) experimented with using pictorial models to teach complex tax rules. Osgerby, Marriot, and Gee (2018) used visual metaphor with accounting students in the context of personal development planning. One interesting strand of accounting education research has examined concept mapping (Leauby, Szabat, \& Maas, 2010; Leauby \& Brazina, 1998; Greenberg \& Wilner 2015). Concept maps provide a visual aid to make information about accounting concepts and the interrelationships between them easier to understand. Concept maps are aimed to benefit both students and teachers, taking however the teaching content perspective as a starting point. In a review of visual research in accounting, Davison (2015) concludes that research has lagged behind sophisticated visual business practices. In a similar vein, Quattrone (2009) states that accounting researchers have had the tendency to study accounting as numbers, texts, and discourse, but have not devoted enough time to exploring accounting as a producer of pictures and images. In addition to these critical observations, suggestions for further research on how practitioners use visual representations have been made. Garreau et al. (2015) states that using visuals has benefits in processing and conveying information, favoring holistic presentation and reifying social realities. Busco and Quattrone (2014) explored the power of the visual elements of the balanced scorecard. They suggest that further research is needed on the role of accounting visualizations in the construction of financial realities and the forms of understanding in the context of visual images.

This paper responds to the previously presented calls for research and aims to further our understanding through reporting on the use of visual representations in teaching accounting for practicing managers. Drawing is used as a novel pedagogical approach in exploring how participants' previous experiences, beliefs, and understandings (and becoming more aware of them) could be related to the learning process on a personal level.

\section{Methods and data}

\subsection{Drawing as a method}

Visual research methods are established practices in qualitative research and cover a range of approaches, including using images and videos, maps, illustrations, etc. However, they are used in reporting data more often than in collecting it from participants. Drawing, one of the approaches in visual methods where the visual data are generated by the respondents, has been used in several areas of study in social research (Mitchell, Theron, Stuart, Smith, \& Campbell, 2011). Kearney and Hyle (2004) have examined the benefits of participant-produced drawings in the context of an educational institution from the participants' perspective. They suggest that using drawings can lead to a more succinct presentation of the participants' experiences, which is a conclusion echoed by Meyer (1991), who states that "people possess more complex, subtle, and useful cognitive maps of their organizations than they can verbalize." Stiles (2004) states that the use of pictorial representation is still, despite its potential, an underused approach in qualitative research. He suggests that images can be as valuable as words or numbers in exploring organizational contexts.

Zweifel and Van Wezemael (2012) have suggested that drawing could be used with interview data to improve the research process. Copeland and Agosto (2012) proposed using graphic elicitation in combination with techniques encouraging participants to provide other contextual explanations. Interviews rest on the assumption that it is the researcher that manages to approach the issue with meaningful questions (Denzin \& Lincoln 1994). Introducing drawing to supplement a qualitative interview method offers interviewees an opportunity to outline the issue from their perspective and the chance to escape the linearity of the spoken word. A drawing produced by the interviewee can also be beneficial for the interviewer by triggering discussions, forming a map of the essential elements, making it easier to come back to those elements and to address their interrelations. Using drawing methodology in combination with interviews can help respondents become aware of their perceptions and beliefs and reveal thought processes that would not necessarily have been spoken. Previous studies point to findings that drawing is helpful in triangulating data using other methods and that drawing can be useful in eliciting data related to emotional experiences (Literat, 2013; Young \& Barrett, 2001).

In addition to enhancing the interview process, drawing has been used in research settings where the respondents are not that able to express themselves verbally. Drawing has been suggested as an approach when studying complex organizational settings with various actors and fuzzy processes (Zweifel \& Van Wezemael, 2012). In such settings, speech might be an insufficient way to present nonlinear contexts and the multidimensional relationships of various actors. Vince and Broussine (1996) asked middle managers to draw pictures that expressed their feelings about change in their organization. They concluded that the drawings led to learning and development by catalyzing the revelation of the unspoken. In a similar vein, Kantrowitz (2012) has described the act of drawing as "the creation of a physical space to play with our thoughts." 
A few studies have used drawing in the context of professional development and learning. Producing visual representations has been used to highlight the learners' perspective. Bowen (2016) explored how internship students visually conceptualized the process of becoming professional in a work-integrated learning program. He used drawing in combination with interviews in understanding students' professional identity construction. Bryans and Mavin (2006) used participantgenerated drawings to explore how business school researchers view the research learning process. They concluded that drawing pictures made the respondents more aware of their own thoughts and opinions. Han and Liang (2015) gathered visual data in addition to interviews by asking EMBA students to draw a graphic representation of their life and to reflect on their EMBA experience. Clarke and Holt (2017) used participant-generated drawings to examine how entrepreneurs used metaphor to make sense of their entrepreneurial identity. Their study has a similar focus as current research in that they also focus on the individual, exploring how the respondents themselves express their identity and understandings in their drawings.

Drawing as a qualitative research method does have some limitations. Some people might decline the invitation to draw images. It can be more challenging to engage with a drawing assignment than to express yourself with spoken words in an interview. People that are less accustomed and skillful in drawing might find participating in producing data more challenging, thereby reducing its quality. Visual data can also be challenging to analyze. Due to the risk of misinterpretation, especially if an analysis relies solely on isolated drawings, an analysis of the drawer's explanations adds reliability. This risk of misinterpretation when analyzing drawings alone partly explains why visual data are often used in combination with interview data.

Bell and Davison (2013) have reviewed the use of visual research methods in management studies and concluded that the use of visual methods is developing rapidly. They describe the potential of visual methods as part of a transition from the linguistic to the visual path in management studies. This study aims to contribute to this growing area of research by exploring drawing as an alternative to words and numbers in developing the understanding of organizations and their management. Much of the previous use of drawing methods concentrates on using it to supplement interviews (e.g., Bowen, 2016; Han \& Liang, 2015; Zweifel \& Van Wezemael, 2012). This paper aims to explore whether visualization of inner worldviews through drawing could provide an actual purpose for doing so, instead of merely supporting other data collection. By employing qualitative modes of enquiry, we attempt to illuminate the potential of drawing in management education.

This study is exploratory and interpretative in nature. The focus is on the individual respondents and the use of drawing in making their understandings of their managerial work context more explicit. This research setting is largely inspired by the phenomenological research tradition (Laverty, 2003), in which studies are concerned with understanding how the world is experienced (Manninen, 1995). By focusing on understanding the world from the perspective of those living in it, the paper seeks to approach the phenomenon without strong a priori assumptions, definitions or theoretical frameworks. Moreover, as in the phenomenological research traditions, after facilitating the visualization of the managerial contexts participants work within, this research sees the respondents as co-constructors of the interpretations of the study.

\subsection{Drawing assignment and data analysis}

The drawing assignment was introduced in an Executive MBA accounting course in Finland in the fall of 2017. The EMBA program in question was launched in 1989 and attracts experienced managers nationwide. More than 1000 students have completed the program, which is internationally accredited by the Association of MBAs (AMBA). The aim was to explore the use of drawing to illustrate participants' work from an accounting perspective. This places an emphasis on the selected participants' professional profile since the current work role is the necessity on which the visual representation is built. Background information about the participants was collected (including age, education, organization, job title, work experience in years and so on). The average age of the respondents was 43.5 years and they represented various fields of industries, including the public sector. All the participants in the EMBA accounting course in question were experienced managers studying part-time alongside their managerial work, so they were therefore eligible to be included in the experiment. Descriptive details of the participants are presented in Appendix 1.

The assignment was implemented at the very beginning of the accounting course, so that the accounting content taught would not affect the respondents' thinking. The respondents were not forewarned about the assignment. The assignment was separate from the official course completion requirements and course work and was not graded. The participants were guaranteed that their input would be anonymous. The time allotted for the drawing activity was 20 min. The researcher moved away from the respondents while they were drawing, but remained in the room. The assignment given to the respondents was to produce a drawing illustrating their managerial work from an accounting perspective. They did this individually without being influenced by others. They were told that the assignment would not be graded and that the purpose was to explore drawing as a method for thinking and learning. The explanation stressed that the aim was not to elicit skillfully crafted artistic drawings, but visualizations reflecting their view on their work from an accounting perspective. The respondents were provided with several sheets of paper, and they were permitted to make drafts or sketches if they chose to. In addition to the final illustration, the respondents were asked to provide further information about their drawing in writing.

Researchers had an essential role in facilitating the drawing assignment. Their role was to prepare the drawing instruction, which was given to students, supervise the exercise, collect drawings, analyze and interpret the drawings before the next seminar, determine categories for the drawings, and develop valuable frameworks for discussion. In this experiment, the researchers guided the drawing process as little as possible and therefore were careful even with the wording used in 
the classroom. For instance, we were careful not to use words that may have affected the drawings, thus we chose to avoid terms such as customer, money, and leader in the instructions. The aim was to examine how managers address an assignment like this, and how they visualize their work from an accounting perspective.

All the respondents produced drawings and provided further information in writing. No students expressed reluctance to participate in the experiment. This is probably explained by the profile of the participants and the general setting of the experiment. Executives are used to expressing themselves, and their work means they encounter surprising events far more demanding than this drawing exercise that require a response. In addition, participating in an education program makes them receptive to new experiences. Everybody understood the assignment and was willing to participate, and even excited by the prospect. In total, 20 illustrations were produced by the participants, collected by the researcher at the event, and later analyzed. Respondents were also asked to write briefly about their current managerial role and to describe their drawing in writing. These further contextual explanations were collected to make the analysis of the illustrations more profound and reliable (Copeland \& Agosto, 2012).

This research utilizes an empirically driven visual elicitation approach (Bell \& Davison, 2013) where the data are produced during the process. This research-initiated production of visual data and meanings (Pauwels, 2010) allowed rather contextualized material to be produced-in this case, managerial work from an accounting perspective. The data were analyzed using content analysis in the context of images (Franzosi, 2004), exploring qualitative patterns and themes (Silverman, 2001). The drawings were first examined to determine how they were constructed to express their message. The process was aided by utilizing the written descriptions of the drawings provided by the respondents. After researchers labeled the data with initial theme descriptions, the drawings were categorized according to how the managers approached the issue, rather than on the basis of a detailed analysis, including and omitting nuanced features in the drawings. Content analysis of the data was carried out as suggested by Merriman and Guerin (2006), as a qualitative exploration of what was drawn, as well as quantitatively examining how often particular themes or categories appeared.

The results were presented to the respondents a month later in order to acquire a better understanding of the illustrations. Review of the interpretations with participants (Hatch, 2002) addressed also questions and comments (thus offering a way for students to see how others have portrayed accounting), facilitating general discussion and offering ways to interpret drawings, and linking the ensuing discussion to contemporary accounting topics and frameworks. Moreover, this collective construal approach, where participants discussed the findings with the researchers to make more sense of the drawings, provided further understanding about the participants' experiences of the implementation and outcomes of the experiment. After this consensual validation with the respondents (Patton, 2002), the researchers analyzed the data once more and formulated the final results.

\section{Results}

\subsection{Analysis of the drawings}

In analyzing the data, we observed that almost all the respondents annotated their graphical illustrations (translations are added by the researchers to the pictures), in addition to providing a separate written description of their image, and those additional linguistic meanings enhanced the illustrations. However, the downside was that the annotations often revealed company names or logos, thus prohibiting the use of some of the pictures as public examples, on the grounds of the promised anonymity. The illustrations included in this paper are chosen to represent examples of the formed categories, while respecting the participants' anonymity. In some of the following pictures, names and/or logos of the companies are covered with a black box in order to guarantee the anonymity of the respondents.

We analyzed the drawings to discover patterns, allowing for the drawings to be assigned to three categories. The first category was illustrating the operations, where the main emphasis was on the visualization of business operations and organizational activities. These drawings presented essential actors and organizational entities related to the respondents' managerial responsibilities. Accounting was approached through the dynamics of respondents' managerial work and the activities and actors related to it. Managers aimed to illustrate essential operations, through which the financial outcomes of their work arise, as well as the stakeholders that affect that work. Managerial work, however, takes place in various organizational contexts. Managerial positions are diverse. Drawings in this category acted as a tool in presenting respondents' understandings about their managerial contexts and experiences. Drawing allowed simultaneous perceptions of different actors and relationships, making complex strings of interaction visible and tangible. Produced pictures outline managers' understanding of what constitutes building financial success in a variety of managerial work contexts. The drawings in this first category ("illustrating the operations") were typically constructed as illustrations of networks and actors. Customers were often included, as well as other stakeholders, thus the elements extended beyond organizational boundaries. Fig. 1 shows an example of this by placing the respondent in the middle and illustrating various actors and organizations that have an effect on the profitability of the business the respondent is responsible for.

Fig. 2 shows another example of the first category, showing how drawing was used to radially mind map and label various internal aspects (production, R\&D, sales, and marketing) as well as things outside the organization (customers and partners). In addition, risk management and data analysis were mentioned. Six out of ten illustrations in the category of "illustrating 

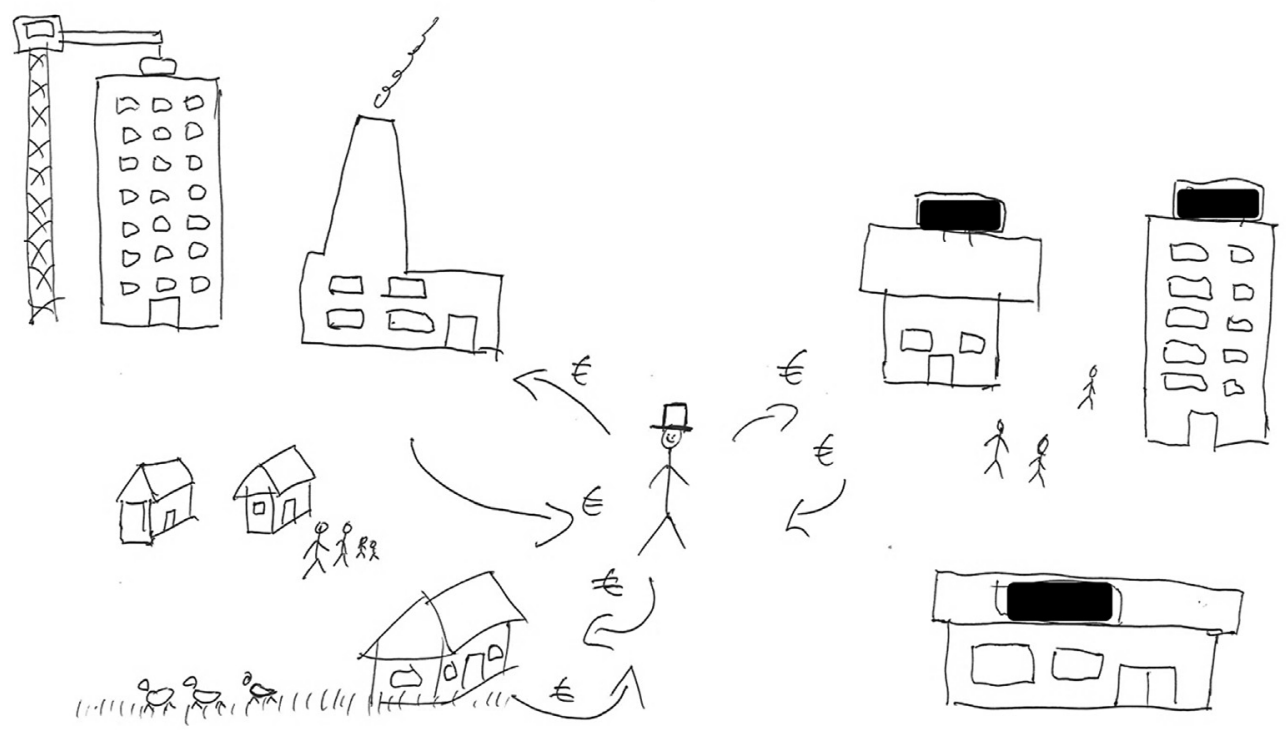

Fig. 1. Drawing by a director in the "illustrating the operations" category.

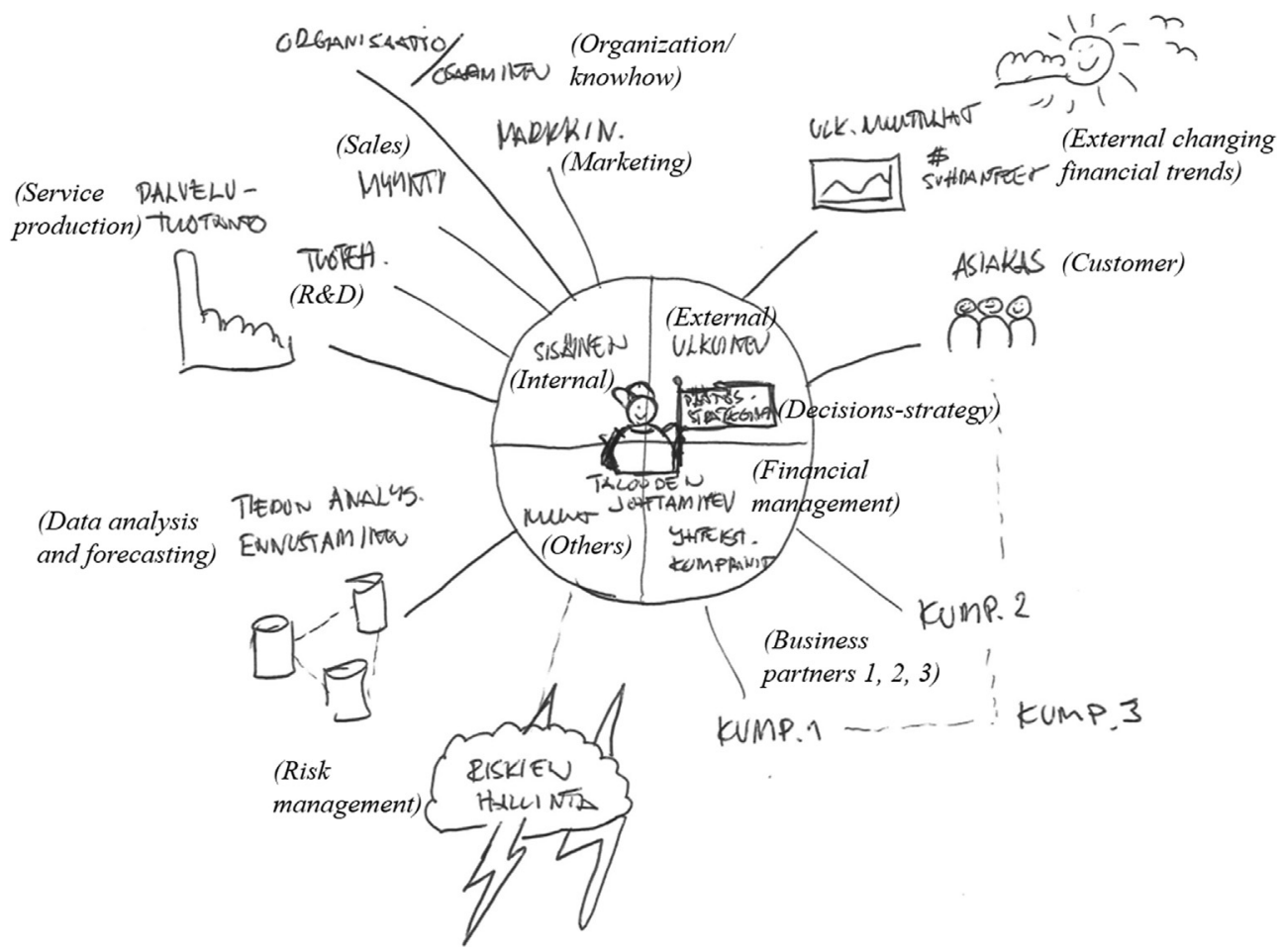

Fig. 2. Drawing by a business director in the "illustrating the operations" category.

the operations" presented the managers' approach this way, mapping different essential elements of their work and business.

Another distinctive approach in the "illustrating the operations" category was a more process-oriented presentation. Four of the ten drawings expressed their work from an accounting perspective like this. Instead of static lines connecting different elements as described before, these drawings included arrows illustrating movement and dynamics of the operations. Fig. 3 exemplifies the "illustrating the operations" category through presenting organizational and business activities in a dynamic manner. 


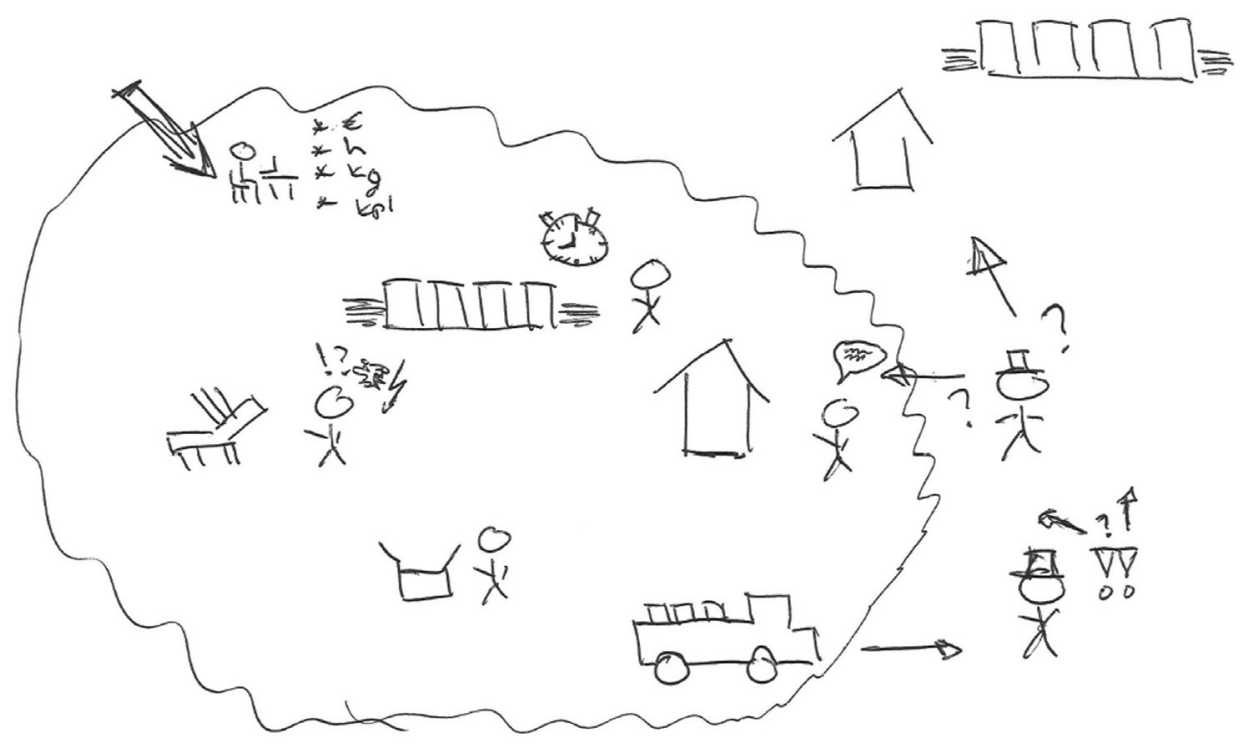

Fig. 3. Drawing by a CEO in the "illustrating the operations" category.

Fig. 4 in this category even resembles a process description, representing a series of actions undertaken to achieve certain outcomes.

The second category was "financial processes," which was applied to the illustrations of eight of the twenty respondents. The illustrations feature more conventional concepts of accounting, in that they describe aspects such as income, costs, cash flow, and the way that accounting issues are handled. Upon examining the drawings, two further subcategories emerged: Five of the drawings outlined the element of profitability in their work, often including extensive written textual information in the pictures. These respondents typically had a business profitability responsibility, meaning that they were accountable for generating revenues in addition to running operations cost-effectively. Fig. 5 presents an example of this kind of

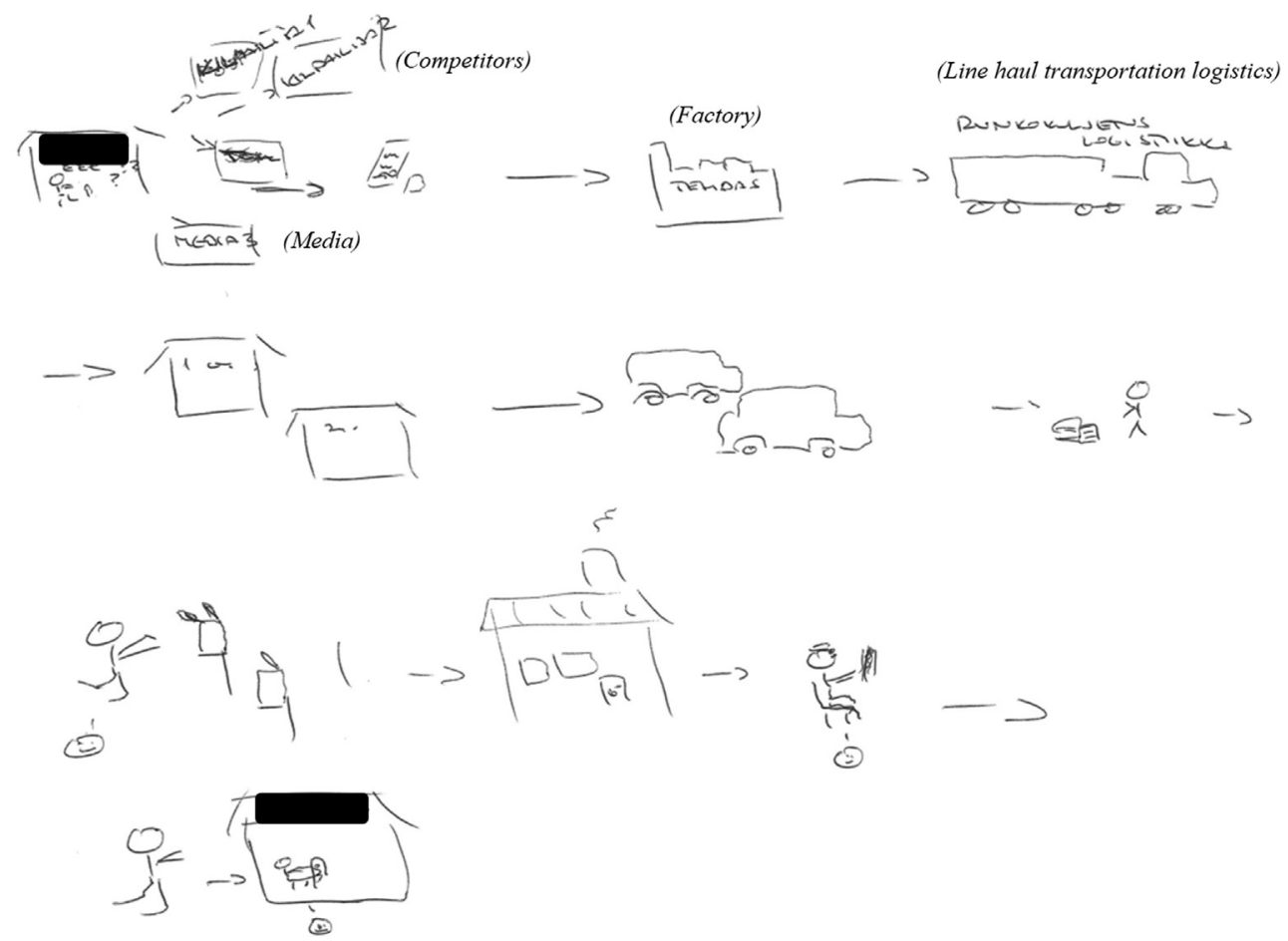

Fig. 4. Drawing by a director in the "illustrating the operations" category. 


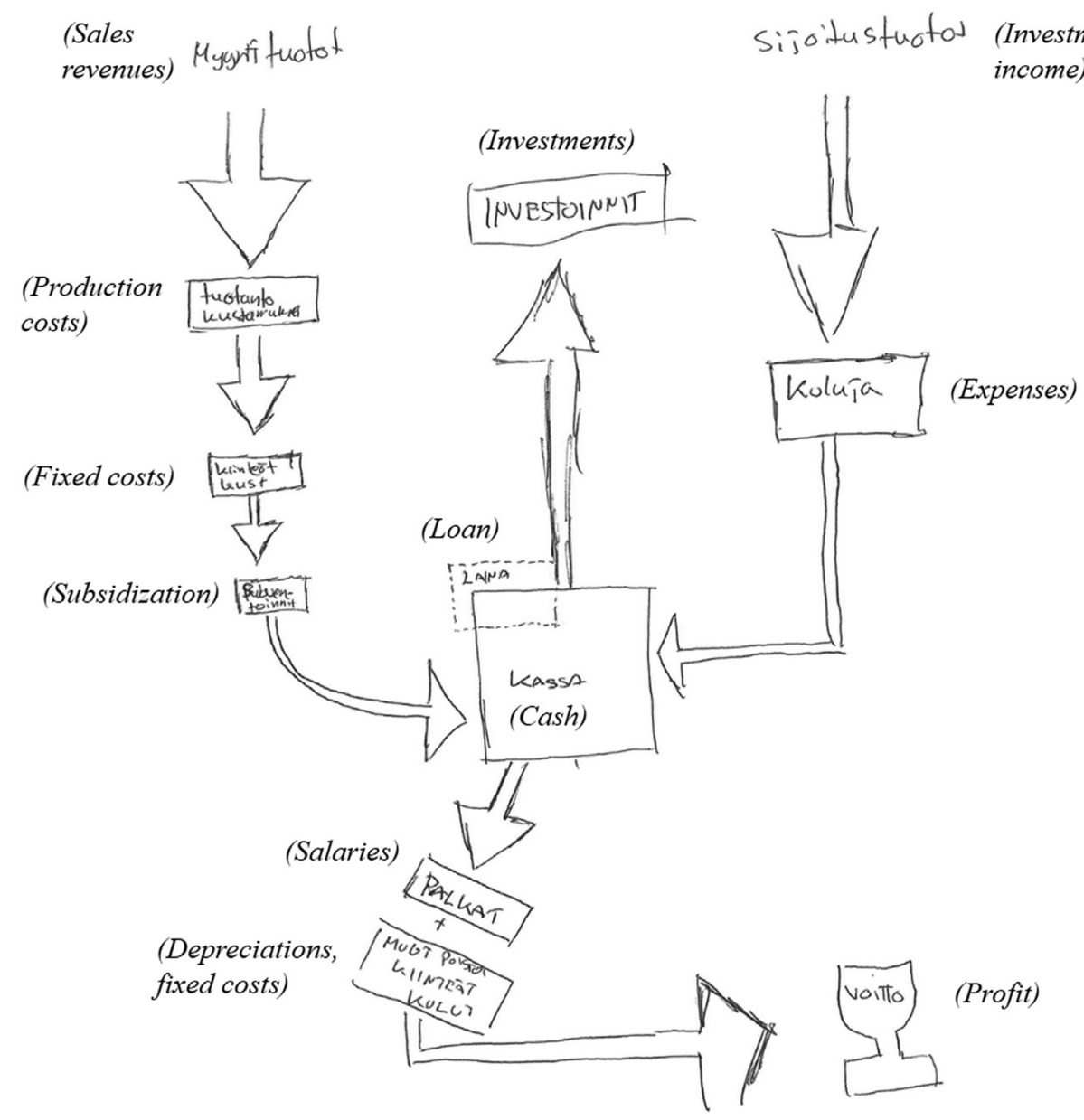

Fig. 5. Drawing by a director in the "financial processes" category.

approach. It illustrates how profit is constituted in the respondents' business, starting from income streams, allocating costs, cash and investments and leading to profit, which is represented by a trophy symbol.

Three illustrations in the "financial processes" category presented the ways in which accounting issues are addressed in the respondents' managerial work. Instead of presenting how profitability is constituted in their operations, these respondents illustrated a cyclical process of how financial issues are monitored and managed in their work. Fig. 6 presents an example of this.

Fig. 7 takes this approach to a more detailed level, illustrating an annual clock in which financial issues such as budgeting, invoicing, and expenses are dealt with throughout the year.

The third category of drawings included only two drawings, but they were nevertheless distinct from the previous categories. These two respondents approached the assignment by illustrating a drawing that we classified as a third category, "visual metaphor." These acted like figures of speech that helped to explain the idea that the respondents had related to accounting and their work. Fig. 8 presents an example of this. It shows the respondent in a rowing boat, aiming to move toward calm waters and sunshine, away from the storm. The respondent further described the drawing in a separate text description by stating that managerial work often feels like this, as involving a challenge to maneuver away from storms.

Both of the drawings in the "visual metaphors" category described managerial work as challenging and pressurized from an accounting perspective-a rather gloomy picture. If not downright pessimistic, these drawings were at least far from presenting a metaphor of wealth. They instead emphasized the challenges of making money in a business context and the pressure that doing so places on managerial work. Fig. 9 presents this by illustrating a scale, balancing factors that enable and restrain the manager achieving aspired financial business outcomes.

In addition to the previous three categories formed through qualitative content analysis, researchers conducted some additional analysis and observations. We examined whether some other aspects connected to the respondents were affecting the classification. Sex, age, educational background, or industry were not found to affect the outcomes. 


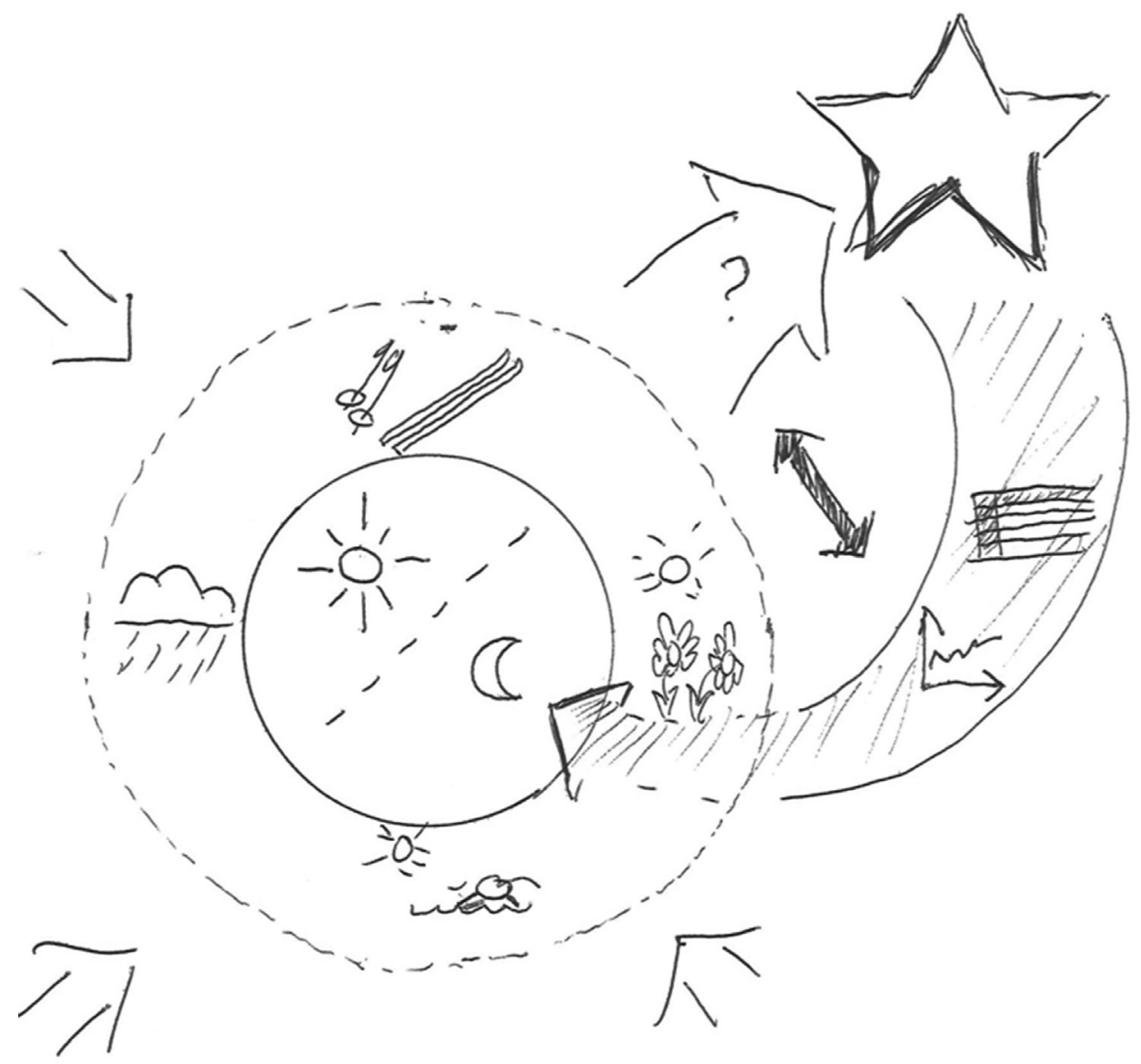

Fig. 6. Drawing by a director in the "financial processes" category.

\subsection{Presenting the results and discussing with the participants}

The month between producing the drawings and the follow-up discussion permitted the respondents to reflect upon the experiment. The results and their categorizations were presented to the respondents, and they discussed the findings in small groups before sharing them with the whole group. Respondents were also asked to discuss the idea of drawing as a learning assignment in small groups and as a whole group. The respondents seemed to be satisfied with how they had approached the assignment and nobody expressed a desire to radically change the structure of their drawing. However, several suggestions were made on how to refine the illustrations if given a second opportunity.

Some respondents felt that their visual presentation could be improved by prioritizing different elements, perhaps by drawing some elements larger than others. It was also suggested that a financial aspect could be attached to the illustrations, for example, by placing a rough estimate of revenues and costs with different elements in the pictures to illustrate the relative importance of different aspects. Another suggestion was that it would be beneficial if the illustrations included a reference to how managers allocated their time across different business activities and if interaction could also be included.

It was also suggested that in order to strengthen the learning aspect, one option could be to produce more than one drawing. In addition to drawing at the beginning of the course to make learning starting points explicit, a second drawing could be produced at the end of the course. It would then be interesting to observe how the illustrations differed in terms of how they reflect the development of the personal and managerial context-dependent understanding of accounting in their work.

A further suggestion was to utilize drawing after each course day. The drawing could be further modified and supplemented in several phases to include approaches from different lectures and materials as the course proceeded. Regarding the temporal extension of the assignment, it was seen that including a visionary aspect in the drawing could be useful as well. As goal-oriented managers, some participants suggested that drawing could be used to specifically illustrate the direction of the desired organizational development. Thus, drawings could progress beyond illustrating the status quo to present how things should be. That might mean drawing another picture to present a new selection of desirable stakeholders, to introduce novel elements regarding the operations and their profitability, and to amend an existing picture by prioritizing certain elements. 


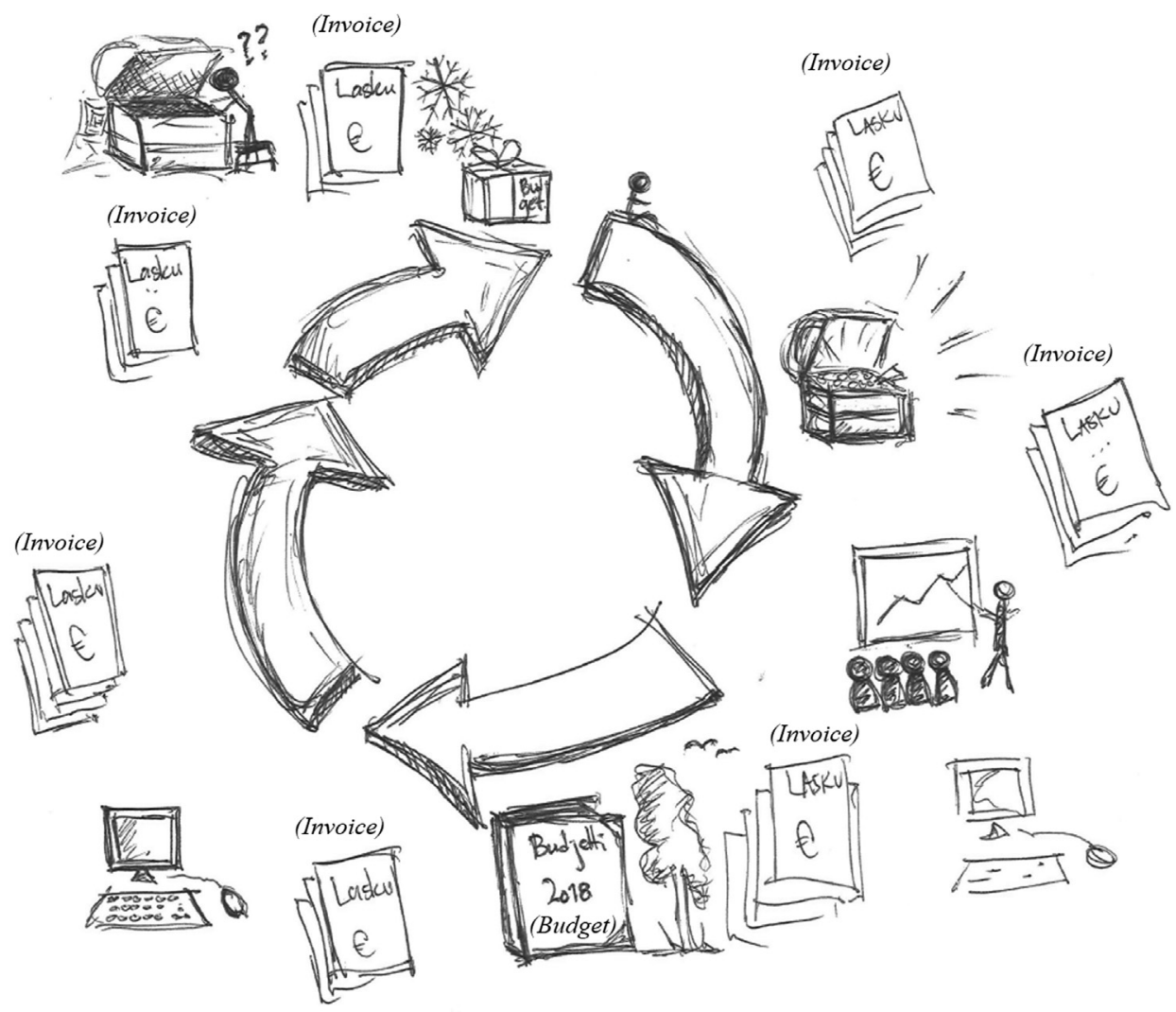

Fig. 7. Drawing by manager in the "financial processes" category.

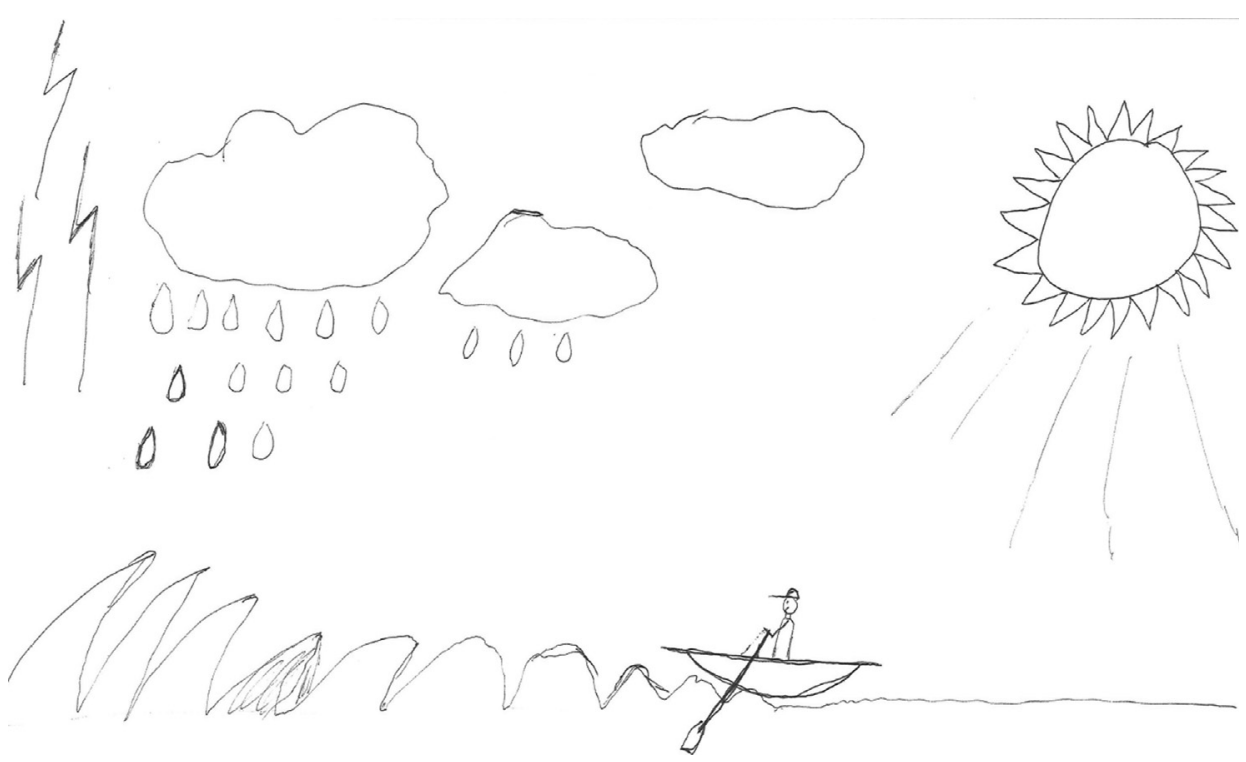

Fig. 8. Drawing by a production director in the "visual metaphor" category.

Overall, the discussion on the findings with the participants added several perspectives to the understanding and further development of the drawing method experiment. In addition to the drawing assignment itself, the planned context of the experiment (in a current accounting course) also inevitably contributed to the extensive range of ideas from the participants. Between the initial drawing assignment and the presentation of the results and discussion, the participants had learned a 


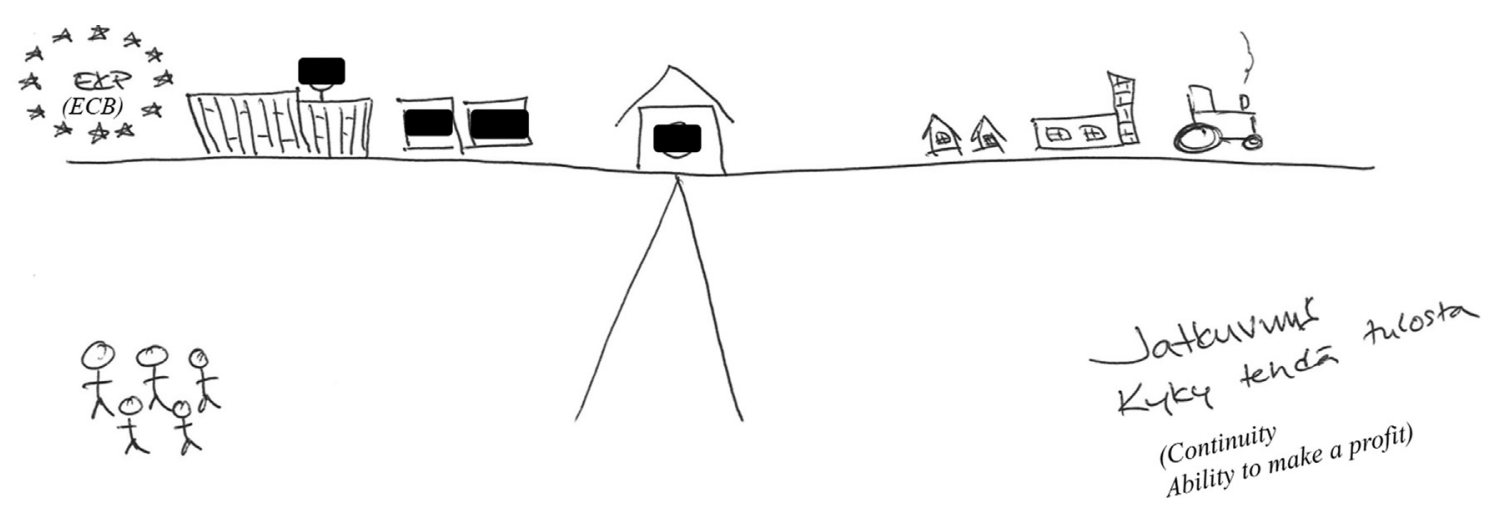

Fig. 9. Drawing by a director in the "visual metaphor" category.

range of accounting concepts throughout the course. Even though their ideas were mainly on how they could personally learn more via the drawing method, their ideas were likely influenced by their improved understanding of accounting in general. Overall, the participants were satisfied with the experiment and thought that it was useful in developing their understanding of accounting in the context of their managerial work. In addition to the drawing data, the ensuing discussion with the participants also proved to be beneficial in exploring the potential of participant-generated drawings in the context of accounting education.

\section{Discussion}

\subsection{Conclusions about the drawing experiment}

Existing research has mainly used drawings alongside interviews. We set out to explore whether drawing could be a valuable approach in itself for facilitating learning. The outcomes of the teaching innovation offer various implications suggesting that using visualization in executive education could open new avenues for learning. The use of drawings in an EMBA classroom created learning through personal experience when producing the drawing and in the process of sharing and discussing the outcomes within the course group.

Drawing encouraged EMBA students to reflect on their thinking from a new and somewhat surprising angle-accounting and drawing are not self-evident companions. Drawing required students to step out of their typical thinking. They were forced to conceptualize their understanding of their managerial work from an accounting perspective. Drawing requires that a person places illustrated elements in relation to each other, chooses which elements are most important and which less central, selects what to show and what to hide, and even outlines causal relationships between different elements. This exercise created a revealing setting for managers to see, in their own drawing, how they construct their reality around accounting. This experience opened routes for valuable reflections, which included the participants questioning whether their illustrations had really captured their understanding in a condensed form, whether-and if so why-they had left something out, why they viewed some elements as more important than others, and whether there was potential to view accounting and their roles as actors in a different way. Previous literature has outlined the distinctive characteristics of drawing compared to speech. Zweifel and Van Wezemael (2012) state that speech forces the speaker to tell a story in a linear way with causalities and hierarchies, whereas drawing allows a person to escape the one-dimensionality associated with the spoken word. The results of this research show that many of the respondents used drawing to exploit space as a second dimension of communication. The most common category-illustrating the operations-presented processes and managerial contexts with various actors and their relationships.

In addition, the collective construal approach, where the outcomes of the drawing exercise were discussed in a group, proved to be valuable. This was a learning experience where students saw how others had illustrated their understanding. By showing all the drawings to all the participants, we created a basis for a unique accounting discussion. Participants saw how others had approached accounting and how they perceived their role in their organizations. The experience was unique in two ways. First, the drawings opened a new perspective to see how others perceived their work from an accounting perspective. Second, drawings differ from chronological stories, in that drawings enable each participant to see the whole story of the others at the same time. In the ensuing discussion and reflection, we also offered ways to interpret different drawings. This is a unique setting in which to see how others portray the main elements of accounting and how a person's own depiction was different from or similar to the other pictures produced. Fig. 10 presents a summary of the drawings, showing the categories formed from the drawing data. 


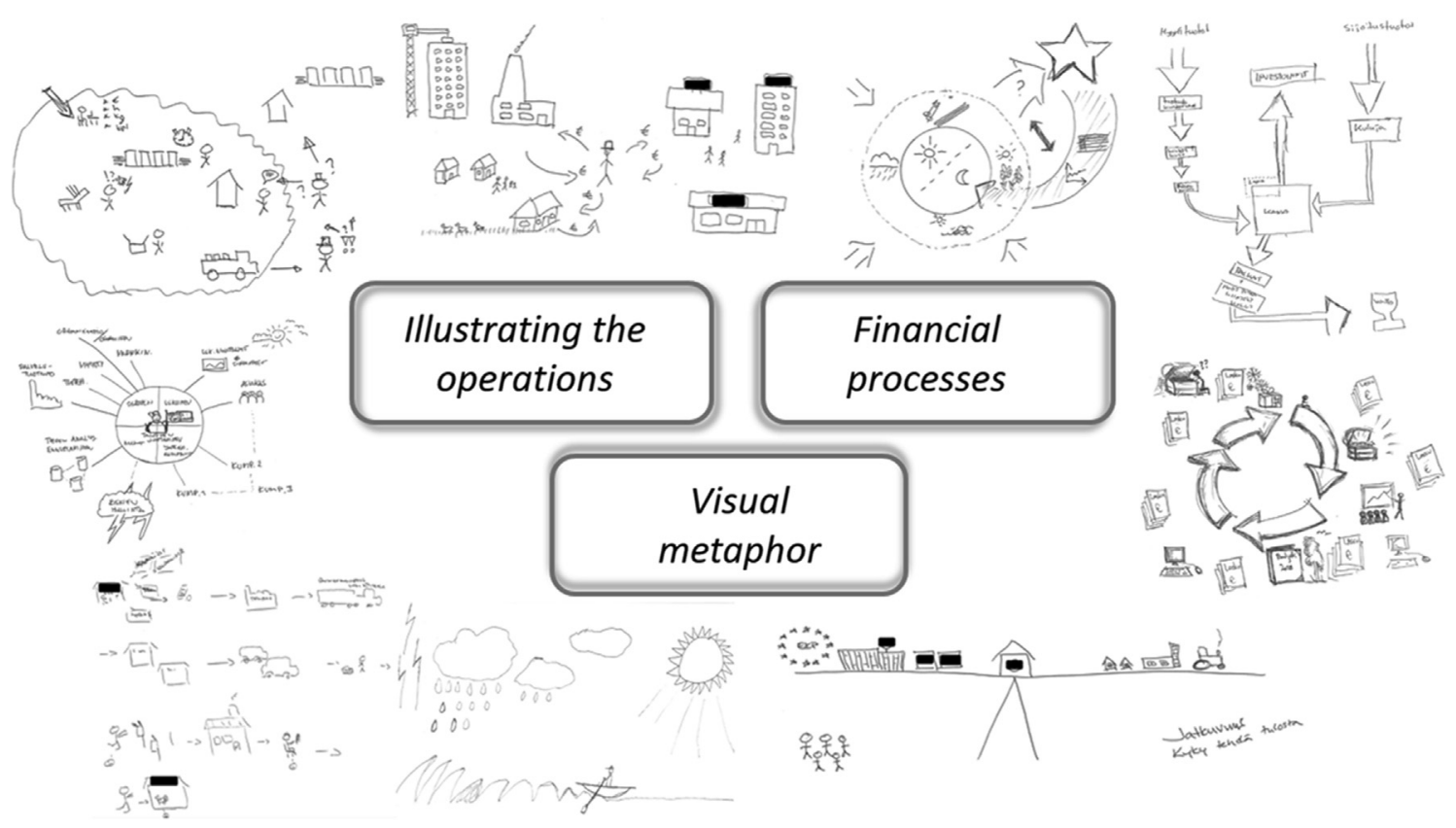

Fig. 10. Three perspectives the participants used to visualize accounting in their work.

\subsection{Further use of the drawing method}

Despite the encouraging outcomes of the drawing experiment, a critical evaluation of the results of this paper offer several suggestions for further use of the drawing method in accounting education. Since this is the first paper, to our knowledge, to report the use of drawing as a learning method in accounting, the suggestions are aimed at modifying the design of the drawing exercise in future use. The following observations are not a comprehensive list of improvements constituting one ideal way of implementing the drawing assignment. Instead, they are a collection of ideas to draw from when planning the use of drawing to improve the learning outcomes.

\subsubsection{Designing the drawing assignment}

When using participant-generated drawings to facilitate learning, the specific assignment given to students is an essential starting point. On this first occasion, we were careful not to guide the drawings in any way. Of course, this is only one perspective on how to use drawing. Various more directed assignments could alternatively be used. In our approach, we implemented the drawing assignment at the beginning of the course. We propose that the beginning of the course is an appropriate place for the assignment, or at least the first stage of it. Drawings can elicit the individual managerial contexts of students, illustrating the premises for learning accounting. However, although the instruction is well placed at the beginning of the course, with experienced managerial students the exact content of the instruction might be reconsidered. In EMBA studies, a typical aim is to strengthen the executive student's role as an active doer and manager in their organization. For this reason, it could be beneficial to advise the students to outline illustrations in a way that would emphasize their personal agency from an accounting perspective. The actor perspective could be strengthened by advising the students to place themselves in their drawing. A more focused briefing preceding the assignment could also promote more refined and informative drawings. This way the drawings could be more effective in portraying how a manager can enhance an organization's financial success and in outlining where the biggest potential for influence may lie. Even with the open-ended assignment we used this time, the drawings could be revisited and students encouraged to place themselves in their picture. Executive students should be able to illustrate specific areas where their actions would be most relevant to the financial success of the organization.

\subsubsection{Implementing the drawing assignment}

In addition to designing the initial assignment, how and where the drawing takes place should be carefully considered. On this occasion, the drawings were produced with a single-color ballpoint pen. Perhaps providing some additional colors could be useful to highlight certain elements in the drawings. In addition, the place where the drawing occurs might have an impact on the type of images produced. Allowing experienced managers to create the drawings independently outside of their formal professional context perhaps encourages deeper levels of reflection. It is essential that the students understand the drawing exercise as a genuine effort in enriching the learning experience. This requires trust and a positive learning 
culture in the educational setting to facilitate individual and collaborative learning. Drawing should not be considered as an exam or a test set by the teacher, but as an exploratory learning journey towards further understanding of accounting.

The temporal timespan of the use of the drawing method offers room for innovation. In this experiment, a drawing approach was used to illustrate the premises for personalized learning by highlighting participants' experiences, beliefs, and understandings of accounting. In this experiment, the respondents' feedback established their desire to develop their own drawing after the initial version. These various suggestions (prioritizing different elements, including the financial aspect, visualizing time allocation and interaction, producing more than one drawing, emphasizing the future in the picture) also convey the message that utilizing the drawing method in multiple stages could be beneficial.

\subsubsection{Facilitation of learning through the produced illustrations}

From a learning perspective, a session where the drawings are presented and discussed together is pivotal and could be utilized in many further ways. The collective discussion and reflection offers ways to interpret different drawings and the ways that students depict themselves as doers and actors from an accounting perspective. The process can be used to offer new opportunities for students to reflect on whether their own role as an actor in accounting appears to be such that they wish to continue. In addition, this session offers an opportunity for the teachers to address a variety of essential accounting issues from a managerial perspective, building on the students' drawings. Teachers have the opportunity to analyze the drawings in advance and prepare to highlight specific features in them and to position these perspectives within the accounting discipline. Additionally, the teacher can address different perspectives on accounting that were not evident in the pictures. Getting familiar with the students' professional context through the drawings and the ensuing joint discussion also connects the teachers with the participants. The practical arrangements of the group discussions could also be improved. For example, instead of the computer presentation slides that we used in this experiment to present the drawings, it might be valuable to prepare a bigger canvas or several canvasses of drawings. This improvement could enhance the learning experience-the experience of seeing the so-called whole picture provided by others at first glance. Here each student would see at a glance how others have visualized their work from an accounting perspective and, possibly more specifically, portrayed their position as an actor in the accounting realm in their organizations.

If the drawing exercise would play a larger and continuous role in the accounting course, personal feedback and reflection support for each student could be offered. The feedback could be based on the teacher's interpretation of the drawing and could highlight how that particular drawing constructs reality and how it is similar to and different from the reality portrayed in other drawings. Learners could further develop their drawings based on the individual feedback from the teacher, ideas gained from understanding other students' drawings and the lessons from the course content. Perhaps the visualizations could be used in discussing accounting issues in a new way also in one's own organization with various people in order to create common understanding and to find new ideas.

Overall, accounting educators should consider using drawing as the creation of a space where students can play with their thoughts outside the confines of their minds (Kantrowitz, 2012), to see their perceptions and understandings in visible form. Facilitating learning in this space opened by individual drawings is novel environment for teachers as well as learners.

\subsection{Theoretical contribution and suggestions for further research}

In addition to responding to the call to utilize pictorial representation more often in research (e.g., Stiles. 2004; Bell \& Davison, 2013), and to explore the use of visuals in the context of accounting (Quattrone, 2009; Busco \& Quattrone, 2014), the teaching experiment reported in this paper addressed a specific theorized, and methodologically located, problem. This research aimed to explore how the previous experiences, beliefs, and understandings of an executive student could be elicited and related to the learning process on a personal level. Despite the suggestion by several prominent scholars that executive learning should be more closely grounded in the managerial work of the participants (e.g. Ruth, 2017; Carvin, 2007; Fox, 1997; Contu \& Willmott, 2003; Tushman, O’Reilly, Fenollosa, Kleinbaum, McGrath, 2007), there is little research on how the learner's experience should be utilized in formulating the learning journey. Additionally, engaging more with practitioners has been suggested to increase the relevance of accounting research and education (Jones, 2017; Cooper et al., 2013; Jönsson, 1998; Hall, 2010). This paper provides an example of how drawing can be used as an approach in personalized learning that is based on the learner's managerial work context. To date, visualizations have been proposed for use in accounting education in the form of concept maps as a way to make instruction or curriculum transparent to students (Greenberg \& Wilner, 2015). However, they could also play a reverse role. The visualizations produced by students can be used to make their initial understandings of a topic more transparent. Visual representation allows a message to come across instantaneously and is immediately processed.

The results illustrate that practicing managers do not enter a learning setting without some experience of the topic (e.g., accounting issues in managerial work). It was noticeable that visualization triggers a sensemaking process of observation, reflection, and evaluation of one's situation (as suggested by Zweifel \& Van Wezemael, 2012). Drawing can be used to make one's own perceptions of complex settings visible (see, e.g., Bryans \& Mavin, 2006; Kantrowitz, 2012). This is connected to the idea of experiential learning (Kolb, 1984), which defines learning as "the process whereby knowledge is created through the transformation of experience." In this approach, all learning can be considered re-learning. Effective managerial learning should be about the manager becoming more aware of his or her previous understandings, examining beliefs, and integrating more refined perspectives into his/her managerial thinking. This study explored the potential for visualization in doing 
this and was the first in the accounting field to report on drawing as a learning method. The results of this study suggest that learning accounting from an executive's perspective can be seen as a need to frame the so-called big picture and to see one's managerial area of responsibility and its development through financial logic. Constituting this understanding should be seen as an ongoing process of constructing and interpreting the dynamics of building a successful business organization as well as of one's personal role in that setting.

Despite the potential offered by participant-generated drawings for education, certain theoretical and practical implications of the method set constraints on its role in the learning process. The chosen theoretical lens of experiential learning provides support for the drawing experiment reported in this paper to work in other settings, but it also defines the boundaries for those contexts. Experiential learning is, by definition, founded on the participant's previous experience. Illustrating managerial work from an accounting perspective is only possible for experienced managers, and even for them it is a demanding exercise. In turn, accounting as a discipline is often taught as a professional qualification for people without any prior experience of the topic. This implies that the learning experiment described in this paper is limited to experienced managers.

This study experimented on how drawing can create a feedback loop that can be used to respond to our ideas and understandings. However, one's previous understandings of accounting, which drawing can help a student become more aware of, should only be a starting point for further learning. Self-produced visual representation can frame a single conceptualization too prevalently and lead to over-commitment to one's pre-existing thinking. Information that supports and is consistent with pre-existing understanding is easily afforded greater priority (Tucker, 2017). This belief perseverance should be carefully considered in accounting education, especially with students who possess limited experience or prior instruction in accounting issues. Because prior understanding is influential, a balanced approach for teaching accounting to experienced managers is needed. The learning of accounting concepts and techniques should be based on more than students constructing their own knowledge and choosing their own learning goals. Although students' existing understandings of a topic are important, the theoretically coherent and logically articulated organization of the topics of instruction should also be considered beforehand (Samuel, 2018). In the case of accounting, a discipline with technical precision, postmodern teaching assuming a level of individual teaching and learning, poses a challenge. Miley and Read (2018) have recently addressed this problematics by describing prioritizing the individual learning experience, while remaining aware of the many constraints on the teaching of accounting, as postmodern pragmatism. This present paper addresses Miley and Read (2018) concern over how traditional teaching approaches fail to engage students by describing an innovative approach for drawing the premises for personalized learning.

The main limitation of this study is that it presents only outcomes that occurred through the process we selected. The drawings could have been made in various other ways and at other points in the course. The drawings were made at the beginning of the course, and then analyzed and discussed. More information could have been gained through further developing the illustrations after the analysis. The challenging and novel nature of drawing as a method for expressing oneself means the respondents were limited in producing data in comparison with more conventional working methods. In addition, the deliberately open-ended briefing preceding the assignment limited the depth of the produced data, because part of the dedicated time for the assignment was allocated to considering how to approach the task. One thing to consider when evaluating the results is that drawing as a method risks overgeneralizing the outputs of the more talented drawers, in a similar way that interview research can be biased toward responses from more articulate informants. Drawing aptitude varies from person to person, limiting the output of the research. This research suggests that in pursuit of personalized managerial learning, drawing can act as an effective tool, expanding the possibilities beyond the traditional written word.

Further research could examine in greater detail the previously described limitations and determine if drawing could address the challenges previously reported (Craig, 2001; Pastra, 2009) in teaching accounting to executive MBA students, thereby facilitating personal and organizational learning. Furthermore, we suggest the use of visualizations in organizational contexts as an important area for future research. In addition to self-evaluating and reflecting on personal understanding triggered by drawing, visualization can also aid the presentation of this understanding to others. When the entire organization is considered as a unit of analysis, verbal data might overwhelm people's information processing capabilities (Meyer, 1991), whereas using visuals might provide an opportunity for developing a collective understanding of a situation. Selfexplanatory and convincing communication is essential in managerial work. We still lack empirical evidence of how practitioners develop sensemaking/giving practices by using visual representations (Meyer, Höllerer, Jancsary, Leeuwen, 2013). Visualizations produced by managers could be a novel approach in co-creating a common understanding of accounting issues in organizational contexts.

Different uses of visualizations (PowerPoint presentations, flipcharts, visual presentations of strategy, etc.) are ever more common in managerial work. This study used a drawing experiment to examine some of the pedagogical implications of introducing drawing as a learning method. We suggest that drawing offers a novel approach and a counterweight to the privileging of language, which has dominated management research and education. Visual expression is different from linguistic expression, which offers an impetus for its use in learning. If every thought or idea could simply be converted into multiple forms of expression, there would be no point in drawing. This offers an intriguing way of illustrating the premises for personalized learning. Drawing can be used in personalization for the learner though tailoring the instructional environment and by the learner, leading to stronger ownership of the learning. The second meaning of drawing-to pull (Pallasmaa, 2009)-points to the essential role of drawing in thinking and learning: to pull out, to reveal and record mental images. 
Appendix A. Descriptive details of participants

\begin{tabular}{lllll}
\hline & Job title & Field of industry & Age & Gender \\
\hline 1 & Business director & ICT & 42 & $\mathrm{M}$ \\
2 & CEO & Finance & 41 & $\mathrm{M}$ \\
3 & Service director & Health care & 45 & $\mathrm{~F}$ \\
4 & Sales director & ICT & 36 & $\mathrm{M}$ \\
5 & REO & Retail & 48 & $\mathrm{~F}$ \\
6 & Sales manager & Manufacturing & 50 & $\mathrm{M}$ \\
7 & Service manager & Health care & 39 & $\mathrm{M}$ \\
8 & Sales director & Marketing Services & 52 & $\mathrm{M}$ \\
9 & CEO & Retail & 44 & $\mathrm{M}$ \\
10 & Leading expert & Health care & 43 & $\mathrm{~F}$ \\
11 & Production director & Energy & 39 & $\mathrm{M}$ \\
12 & Director of administration & Finance & 49 & $\mathrm{M}$ \\
13 & CFO & Services & 43 & $\mathrm{M}$ \\
14 & Director & Education & 41 & $\mathrm{~F}$ \\
15 & Regional director & Finance & 38 & $\mathrm{M}$ \\
16 & CEO & Manufacturing & 39 & $\mathrm{M}$ \\
17 & Unit director & Finance & 54 & $\mathrm{~F}$ \\
18 & Group manager & Retail & 35 & $\mathrm{M}$ \\
19 & Bank director & Finance & 44 & $\mathrm{M}$ \\
20 & CEO & Media & 48 & $\mathrm{M}$ \\
\hline
\end{tabular}

\section{References}

Asik-Dizdar, O. (2015). To be or not to be... a profession: Management education and its discontents. Journal of Education for Business, 90, 443-450. Bennis, W., \& O'toole, J. (2005). How Business Schools lost their way. Harvard Business Review, 96-104.

Bell, E., \& Davison, J. (2013). Visual management studies: Empirical and theoretical approaches. International Journal of Management Reviews, 15, 167-184. Bryans, P., \& Mavin, S. (2006). Visual images: A technique to surface conceptions of research and researchers. Qualitative Research in Organizations and Management: An International Journal, 1, 113-128.

Böer, G. (2000). Management accounting education: Yesterday, today, and tomorrow. Issues in Accounting Education, $15,313-334$.

Bowen, T. (2016). Depicting the possible self: Work-integrated learning students' narratives on learning to become a professional. Asia-Pacific Journal of Cooperative Education, 17, 399-411.

Busco, C., \& Quattrone, P. (2014). Exploring how the balanced scorecard engages and unfolds: Articulating the visual power of accounting inscriptions. Contemporary Accounting Research, 32, 1236-1262.

Brown, R. B., \& Mccartney, S. (1998). Using reflections in postgraduate accounting education. Accounting Education, $7,123-137$.

Carvin, D. A. (2007). Teaching executives and teaching MBAs: Reflections on the case method. Academy of Management Learning E' Education., 6, 364-374.

Clarke, J., \& Holt, R. (2017). Imagery of ad-venture: Understanding entrepreneurial identity through metaphor and drawing. Journal of Business Venturing, 32, 476-497.

Chewning, E. G., \& Spiller, E. A. (1999). Validation of factors relevant to the exemption of accounting courses in MBA programs. Journal of Accounting Education, 17, 123-139.

Cohen, J. R., \& Holder-Webb, L. L. (2006). Rethinking the influence of agency theory in the accounting academy. Issues in Accounting Education, 21, 17-30. Contu, A., \& Willmott, H. (2003). Re-embedding situatedness: The importance of power relations in learning theory. Organization Science, 14, $283-296$.

Collett, N. J. (2000). Innovation or renovation: Effective project design for accounting and MBA students. Accounting Education, 9, 67-92.

Cooper, T., Downer, P., \& Faseruk, A. (2013). Accounting education for MBA students: Beyond debits and credits. The Journal of Contemporary Business Issues, 19, 37-50.

Copeland, A. J., \& Agosto, D. E. (2012). Diagrams and relational maps: The use of graphic elicitation techniques with interviewing for data collection, analysis, and display. International Journal of Qualitative Methods, 11, 513-533.

Currie, G., \& Knights, G. (2003). Reflecting on a critical pedagogy in MBA education. Management Learning, 34, $27-49$.

Craig, R. (2001). Surviving an executive MBA "riot". Accounting Education, 10, 325-327.

David, F. R., David, M. E., \& David, F. R. (2011). What are business schools doing for business today?. Business Horizons, $54,51-62$.

Davison, J. (2015). Visualising accounting: An interdisciplinary review and synthesis. Accounting and Business Research, 45, $121-165$.

Davison, J., \& Warren, S. (2009). Imag[in]ing accounting and accountability. Accounting, Auditing E' Accountability Journal, $22,845-857$.

Denzin, N. K., \& Lincoln, Y. S. (1994). Handbook of Qualitative Research. Thousand Oaks, CA: Sage.

Engstrom, J. H., \& Windal, F. W. (1985). !!

Kolb, D. (1984). Experiential learning: Experience as the source of learning and development. Englewood Cliffs, NJ: PrenticeHall.

Krom, C. L., \& Williams, S. V. (2011). Tell me a story: Using creative writing in introductory accounting courses to enhance and assess student learning. Journal of Accounting Education, 29, 234-249.

Laverty, S. M. (2003). Hermeneutic phenomenology and phenomenology: A comparison of historical and methodological considerations. International Journal of Qualitative Methods, 21-35.

Leauby, B. A., Szabat, K. A., \& Maas, J. D. (2010). Concept mapping-An empirical study in introductory financial accounting. Accounting Education, 19, $279-300$.

Leauby, B. A., \& Brazina, P. (1998). Concept mapping: Potential uses in accounting education. Journal of Accounting Education, 16, $123-138$. 
Literat, I. (2013). “A pencil for your thoughts”: Participatory drawing as a visual research method with children and youth. International Journal of Qualitative Methods, 84-98.

Manninen, A. (1995). The experience of knowledge in everyday accounting: A study of Finnish accounting managers. European Accounting Review, 4, $455-484$.

Merriman, B., \& Guerin, S. (2006). Using children's drawings as data in child-centred research. The Irish Journal of Psychology, $27,48-57$.

Meyer, A. D. (1991). Visual data in Organizational research. Organization Science, 2, 218-236.

Meyer, R. E., Höllerer, M. A., Jancsary, D. J., \& Leeuwen, T. V. (2013). The visual dimension in organizing, organization, and organization research. Core ideas, developments, and promising avenues. The Academy of Management Annals, 7, 487-553.

Minocha, S., Reynolds, M., \& Hristov, D. (2017). Developing imaginators not managers - How to flip the business school model. The International Journal of Management Education, 15, 481-489.

Mintzberg, H. (2004). Managers not MBAs, A hard look at the soft practice of managing and management development. London: Prentice Hall.

Miley, F., \& Read, A. (2018). Pragmatic postmodernism and engagement through the culture of continuous creativity. Accounting Education.

Mitchell, C., Theron, L., Stuart, J., Smith, A., \& Campbell, Z. (2011). Drawings as Research Method. In L. Theron, C. Mitchell, C. Mitchell, A. Smith, A. Smith, \& J. Stuart (Eds.), Picturing Research. Sense Publishers.

Osgerby, J., Marriot, P., \& Gee, M. (2018). Accounting students perceptions of using visual metaphor as part of personal development planning: An exploratory case study. Accounting Education, 27, 570-589.

Pallasmaa, J. (2009). The Thinking Hand: Existential and Embodied Wisdom in Architecture. Wiley.

Pastra, Y. (2009). The rules of the game: Teaching MBA students. Accounting Education, 18, 105-108.

Patton, M. Q. (2002). Qualitative research E' evaluation methods. London: Sage Publications.

Pauwels, L. (2010). Visual sociology reframed: An analytical synthesis and discussion of visual methods in social and cultural research. Sociological Methods E' Research, 38, 545-581.

Pfeffer, J., \& Fong, C. T. (2002). The end of business schools? Less success than meets the eye. Academy of Management Learning Ė Education, 1, 78-95.

Purcell, A. T., \& Gero, J. S. (1998). Drawings and the design process: A review of protocol studies in design and other disciplines and related research in cognitive psychology. Design Studies, 19, 389-430.

Quattrone, P. (2009). Books to be practiced: Memory, the power of the visual, and the success of accounting. Accounting, Organizations and Society, 34, $85-118$.

Ravenscroft, S. P., Rebele, J. E., \& St Pierre, K. (2008). The importance of accounting education research. Journal of Accounting Education, $26,180-187$.

Rebele, J. E., \& St Pierre, K. E. (2015). Stagnation in accounting education research. Journal of Accounting Education, 33, $128-137$.

Roglio, K. D. D., \& Light, G. (2009). Executive MBA programs: The development of the reflective executive. Academy of Management Learning and Education, 8 , $156-173$.

Ruane, M. (2016). Action learning in postgraduate executive management education: An account of practice. Action Learning; Research and Practice, 13, $272-280$.

Rubin, R. S., Dierdorff, E.C. (2009). How relevant is the MBA? Assessing the alignment of required curricula and required managerial competencies. Academy of Management Learning \& Education, 8: 208-224.

Ruth, D. (2017). What is your MBA for? What is your story? Management Learning, 48, 7-22.

Samuel, S. (2018). A conceptual framework for teaching management accounting. Journal of Accounting Education, 44, $25-34$.

Schadewald, M., \& Limberg, S. (1992). Using pictorial models to teach complex tax rules: An experimental investigation. Journal of Accounting Education, 10 , 133-149.

Silverman, D. (2001). Interpreting Qualitative Data: Methods for Analysing Talk. Text and Interaction: Sage Publications.

Stiles, D. R. (2004). Pictorial representation. In C. Cassell \& G. Symon (Eds.), Essential guide to qualitative methods in organizational research (pp. 127-139). London, United Kingdom: Sage.

Tucker, B. P. (2017). Figuratively speaking: Analogies in the accounting classroom. Accounting Education, 26, 166-190.

Tushman, M. L., O’Reilly, C., Fenollosa, A., Kleinbaum, A. M., \& McGrath, M. (2007). Relevance and rigor: Executive education as a lever in shaping practice and research. Academy of Management learning \& Education, 6, 345-362.

Vince, R., \& Broussine, M. (1996). Paradox, defense and attachment: Accessing and working with emotions and relations underlying organizational change. Organization Studies, 17, 1-21.

Young, L., \& Barrett, H. (2001). Adapting visual methods: Action research with Kampala street children. Area, 33(2), 141-152.

Zweifel, C., \& Van Wezemael, J. 2012. Drawing as a qualitative research tool: An approach to field work from a social complexity perspective. Tracey: Drawing and Visualisation Research, May 2012, Retrieved from http://www.lboro.ac.uk/microsites/sota/tracey/ journal/edu/2012/PDF/ Christina_Zweifel-TRACEY-Journal-DK-2012.pdf. 